\title{
Correction: Light Intensity Improves Growth, Lipid Productivity, and Fatty Acid Profile of Chlorococcum oleofaciens (Chlorophyceae) for Biodiesel Production
}

\author{
Marzie Rayati ${ }^{1} \cdot$ Houman Rajabi Islami $^{1} \cdot$ Mehdi Shamsaie Mehrgan ${ }^{1}$ \\ Published online: 1 September 2020 \\ (C) Springer Science+Business Media, LLC, part of Springer Nature 2020
}

Correction to: Journal of BioEnergy Research (2020)

https://doi.org/10.1007/s12155-020-10144-5

The original version of this article unfortunately contained incorrect data in Fig. 2 caption.

The original version has been corrected.

Publisher's Note Springer Nature remains neutral with regard to jurisdictional claims in published maps and institutional affiliations.

The online version of the original article can be found at https://doi.org/ 10.1007/s12155-020-10144-5

\footnotetext{
Houman Rajabi Islami

rajabi.h@srbiau.ac.ir; houman.rajabi@yahoo.com

Marzie Rayati

Marzieh.rayati@srbiau.ac.ir

Mehdi Shamsaie Mehrgan

m.shamsaie@srbiau.ac.ir

1 Department of Fisheries, Science and Research Branch, Islamic Azad University, P.O. Box: 14515-775, Tehran, Iran
} 